\title{
Health Paradox of Indigenous people in Bangladesh: Unravelling aspects of mass media campaigns in changing health behaviors to prevent non-communicable diseases
}

\author{
Reshman Tabassum
}

Master of Research candidate, Faculty of Business and Economics, Macquarie University, Sydney, Australia.

\begin{abstract}
Bangladesh, a developing country, has one of the highest rates of age-standardized mortality due to noncommunicable diseases (NCDs). The prevalence of NCDs is steadily increasing within all population groups, including indigenous communities in Bangladesh. Indigenous people, non-dominant communities of society, are individuals having distinctive social, economic or political systems, and preserving own languages, cultures and beliefs. Contemporary research proposes that negative health behaviors, especially tobacco use, unhealthy diets, physical inactivity, and alcohol consumption are becoming escalating problems in Bangladesh. Indigenous communities with low health literacy are less receptive to health information and are unlikely to embrace positive health behaviors. Three major barriers to change health behaviors toward preventing NCDs among indigenous people in Bangladesh are: unawareness of the severity and/or importance of NCDs; absence of health literacy or knowledge on NCDs; and lack of advocacy for health intervention programs for indigenous patients suffering from NCDs. Intertwined within socio-economic delusions and discrepancies, indigenous people miss out on health care to prevent NCDs. Mass media campaigns have both an extensive coverage and an awareness-constructing potential to educate and influence intended audiences' attitudes on changing health related behaviors. Bangladesh can change health behaviors within indigenous communities by adopting some effective strategies, including using multifaceted mass media to intensify coverage of the health campaigns, underpinning stereotyping health beliefs and conveying unidentified details about NCDs, and developing risk-reduction strategies for indigenous patients suffering from NCDs. Multi-stakeholder and intergovernmental mechanisms and mass media campaigns can be effective options for changing health behaviors of indigenous people in Bangladesh.
\end{abstract}

Keywords: Non-communicable diseases, Mass media, Health behavior, Indigenous people, Bangladesh.

\section{Introduction}

Non-communicable diseases (NCDs) are the leading cause of global morbidity and mortality. ${ }^{1}$ NCDs, including cardiovascular and chronic respiratory diseases, account for around $60 \%$ of overall death in the world, with nearly $80 \%$ of the deaths occurring in developing countries. ${ }^{2}$ South Asia (Bangladesh, India, Pakistan, Nepal, and Sri Lanka) embodies a greater portion of the developing world, and is extensively affected by the upsurge of the burden of NCDs. Some studies were conducted on NCD prevalence in South Asian countries, especially in both industrialized settings, ${ }^{3}$ and urban and rural regions of India. ${ }^{4,5}$ Coinciding with aforementioned studies on NCD burden, research was carried out in Indonesia, ${ }^{6}$ Bangladesh, ${ }^{7,8}$ and Vietnam. ${ }^{9}$ However, the most of these studies fell short to identify the underlying risk factors of NCDs among indigenous people. Although there are extensive reports on the intensified prevalence of diabetes and/or hypertension among indigenous populations worldwide, ${ }^{10,11}$ few studies have been carried out to change their health behaviors for the prevention of NCDs.

Indigenous people are individuals having distinctive social, economic or political systems, and preserving own languages, cultures and beliefs. ${ }^{12}$ Recent studies in Bangladesh showed high prevalence of hypertension $(23.7 \%),{ }^{13}$ diabetes $(7.4 \%),{ }^{14}$ and co-morbid depression

\section{Practice Points}

- NCD prevalence is steadily increasing among indigenous people in Bangladesh.

- Indigenous communities with low health literacy are less receptive to health information and are unlikely to embrace positive health behaviors.

- Three major barriers to change health behaviors toward NCDs among indigenous people are identified: lack of awareness, absence of health literacy, and insufficient advocacy for health intervention programs.

- Bangladesh can change health behaviors among indigenous communities by using multifaceted mass media, underpinning quintessential health beliefs, and conveying unidentified details about NCDs.

- Intergovernmental mechanisms with effective monitoring can play a vital role in changing health behaviors of indigenous people in Bangladesh.

among indigenous patients with diabetes $(61.9 \%){ }^{15}$ The prevalence of smoking cigarette among men in

Correspondence: Reshman Tabassum, Master of Research candidate, graduated with a master's degree from Macquarie University, NSW, 2109, Australia. Email: reshmantabassum3@gmail.com.

South East Asia Journal of Public Health 2016;6(2):17-22. (C) 2016 Tabassum, publisher and licensee Public Health Foundation Bangladesh. This is an Open Access article which permits unrestricted non-commercial use, provided the original work is properly cited. 
Bangladesh was $50 \cdot 3 \%{ }^{16}$ compared to $34 \%$ and $36 \cdot 5 \%$ in Pakistan ${ }^{17}$ and India ${ }^{18}$ respectively. Additionally, the prevalence of chewing oral smokeless tobacco among men was $16 \cdot 3 \%$ and women was $21.4 \%$ in Bangladesh, ${ }^{16}$ whereas the prevalence of consuming oral tobacco was overall $10 \%$ in Pakistan. ${ }^{17}$ Harnessing with the shifting epidemiological profile, contemporary research proposes that negative health behaviors, including tobacco use, unhealthy diets, ${ }^{19}$ physical inactivity, and alcohol consumption ${ }^{20}$ are becoming escalating problems in Bangladesh.

Mass media campaigns have both an extensive coverage and an awareness-constructing potential to educate, and influence intended audiences' attitudes on changing health related behaviors. ${ }^{21}$ Most of the mass media campaigns have not only embarked on tobacco use and heart-disease prevention issues, but have addressed cancer, and sexually-transmitted disease preventive methods. $^{22}$ Several studies have also revealed that exposure to mass media plays an important role in the utilization of maternal health care services (MHCS) ${ }^{23,24}$ and NCD preventive services. ${ }^{25}$ Despite the advantageous of mass media campaigns around the world, Bangladesh is yet to realize the positive facets of mass media campaigns for changing health behaviors ${ }^{26}$ to prevent NCDs within indigenous communities.

It is acknowledged that the topic is vast, with many perspectives. Because of limitations of space and indeed, of the existing studies, this review is an overview, based and centered on NCD burden among indigenous people in Bangladesh. The aim of this paper is to scrutinize different facets of mass media campaigns in changing health behaviors to prevent NCDs within indigenous communities in Bangladesh.

A search of PubMed and Ovid Medline (January 1994 to January 2017), and other search engines were conducted to retrieve potentially relevant studies on NCDs among indigenous people. Databases were searched for English-language articles using key words including: 'Bangladesh', 'non-communicable disease', 'indigenous people', and 'mass media'. The paper excluded any spiritual, emotional, and environmental factors that might be associated with changing health behaviors among indigenous people. Four major areas highlighted in the studies are: an overview of indigenous people in Bangladesh; health care disparities within indigenous communities in Bangladesh; key barriers to change health behaviors among indigenous people; and effective strategies to prevent NCDs.

\section{Indigenous people in Bangladesh}

Indigenous communities signify a rich diversity of traditions, religions and histories, but still remain the world's most trivialized people. ${ }^{12}$ Scarcity of ethnographical data on indigenous people shrinks the chances of getting a clear picture of the underrepresented communities of Bangladesh. The total population of indigenous communities in Bangladesh was projected to be more than 2 million in $2010 .^{27}$ The major tribes, Chakma, Marma, and Tripura, consist of a population of $0.253,0.154$, and 0.08 million people respectively. ${ }^{28}$ Around 45 groups of indigenous people live in southeastern, northwestern, north-central and north-eastern areas of the country. The percentage of indigenous population in 64 districts of Bangladesh fluctuates from less than $1 \%$ in majority of the districts to $56 \%$ in Rangamati, $48.9 \%$ in Kagrachari, and $48 \%$ in Bandarban in the Chittagong hilly regions. ${ }^{29}$

Majority of indigenous communities live in rural and isolated locations, usually far away from urban opportunities. ${ }^{30}$ Local radio and television ${ }^{31}$ are two successful communication vehicles among indigenous people in Bangladesh, allowing the values to ramble within their localities. For example, Garo, an indigenous community, is more inclined to listening to radio than watching television due to the popularity of this communication medium. ${ }^{31}$ People living in tribal areas are susceptible to ill health due to low socioeconomic status and low levels of awareness, and lack of access to preventive aspects of care, which aggravates their health situation. ${ }^{27}$ Existing research has also consistently shown that indigenous people with lower health literacy lack in knowledge about diseases and are incapable of taking care of themselves properly. ${ }^{32,33}$ For instance, Mru and Garo tribes, ${ }^{27,34}$ who live below poverty line, have a tendency to under report their illness and health condition. ${ }^{27}$ In addition, several research on $\mathrm{Mru}^{27}$ and Santal $^{35}$ indigenous communities showed that distinctive geographic location and rural lifestyles were influential factors for their insufficient access to health care facilities, ${ }^{27}$ as well as unhealthy behaviors leading to NCD risks. ${ }^{26}$ Thus, unhealthy practices affect indigenous peoples' health condition and status adversely.

\section{Health care disparities: nature and dynamics}

Indigenous people, the minority communities, are traditionally dominated and discriminated, which has subliminally been affecting their health condition. Studies manifest that indigenous population suffer more from disease burden and health inequalities relative to mainstream population. ${ }^{36,37}$ The disease burden is swayed by numerous factors, including low levels of education, and unwillingness to seek out effective treatment in primary stages of illness. ${ }^{27}$ Mru women, for example, are deprived of health facilities as a result of illiteracy, and disparities in health care services. ${ }^{24}$ Another significant research on Santal tribe illustrated that insufficient health education and attitude were closely associated with lack of knowledge about predisposing factor for the development of Urinary Tract Infection (UTI). ${ }^{27}$ The other reason behind indigenous peoples' poor health is their sedentary lifestyle and unhealthy food habits. ${ }^{19}$ Studies conducted by Biswas et al. ${ }^{20}$ and Zaman et al. ${ }^{19}$ on alcohol consumption and unhealthy lifestyle within indigenous communities have embarked on important public health issues. One study showed that indigenous participants (91) who consumed alcohol were mostly geriatric $(43.6 \%)$ and adults $(37.8 \%){ }^{27}$ The study further analyzed their smoking behaviors and tea habits, thus displaying 43.2\% (99) regular smokers among indigenous participants. ${ }^{27}$

Previously the common communicable diseases prevailed within indigenous communities were mostly measles, whooping cough, smallpox and tuberculosis, and pneumonia. ${ }^{27,38}$ In the modern era, however, Bangladesh is undergoing an epidemiologic transition where the burden of disease is shifting toward NCDs, for example, heart disease, hypertension, cancer, kidney 
disease and depression. ${ }^{33,38}$ Indigenous communities are affected by health complications, thus experiencing higher maternal and NCD related morbidity and mortality compared to non-indigenous people. ${ }^{36}$ One study showed age-standardized prevalence of diabetes was significantly higher among tribal population $(8.4 \%$, $95 \%$ CI 6.48 - 10.37) compared with non-tribal population of Bangladesh (3.8\%, 3.12-4.49). ${ }^{39}$ Research results (higher cholesterol and obesity) suggest that insulin resistance is perhaps a significant contributor to diabetes among indigenous people. ${ }^{39}$ Frequency of diabetes among indigenous people also points toward aggregating trend of NCD burden and complications in Bangladesh. ${ }^{35}$ Another research carried out by Fatema et al. on cardiovascular risk factors among Santal population in Bangladesh indicated that the prevalence of hypertension among males and females was $15.6 \%$ and $7.2 \%$ respectively. ${ }^{40}$ Hence, indigenous patients with NCDs are expected to be marginalized, as the disease epidemic matures and paves the way for inequalities in health care.

\section{Barriers to change of health behaviors}

The first barrier to change health behaviors toward preventing NCDs among indigenous people in Bangladesh is the unawareness of the severity and/or importance of NCDs. Although chronic obstructive pulmonary disease (COPD) and hypertension are significant public health challenges in Bangladesh, ${ }^{41}$ The National NCD Risk Factor Survey of 2010 showed that about $11 \%$ of women and $8 \%$ of men did not seek any treatment for NCDs in Bangladesh. ${ }^{42}$ The avoidance or delay in seeking medical care within indigenous communities remains more acute, especially considering their perception about health and illness. ${ }^{27}$ Evidence revealed that health awareness can minimize inequalities through well designed mass media campaigns, explicitly aiming to reach out the disadvantaged social groups or indigenous communities. ${ }^{1,30,43}$ A study carried out by Rahman et al. on tribal communities in Bangladesh displayed that girls, the most vulnerable group, lacked ample opportunities to discuss about their health and well-being. ${ }^{44}$ Health care programs ${ }^{46}$ are an effective approach to reduce NCD burden and unhealthy habits, while ensuring universal accessibility to health care services for indigenous people. ${ }^{43,45}$ Indigenous people in Bangladesh, however, are unaware of such behavioral programs and are oblivious in seeking medical treatment for any NCDs.

The second barrier to change health behaviors toward preventing NCDs among indigenous people in Bangladesh is lack of health literacy ${ }^{32}$ or knowledge on NCDs. ${ }^{27}$ Evidence from different nations revealed that there is a link between low birth weight and frequency of NCDs in adulthood, ${ }^{47}$ allowing an upsurge in the advancement of NCDs in the future life. ${ }^{48}$ Bangladesh recurrently suffers from insignificant health information and/or education, and a fragile health framework for NCDs, especially a general apathy toward preventive measures. ${ }^{49}$ Some significant studies showed that indigenous women's education was an important factor associated with utilizing MHCS. ${ }^{50,51}$ Indigenous people with poor health literacy or ethnic communities with inadequate access to health information ${ }^{27}$ are perhaps doubtful of remedial advices on NCDs, which escalates their negative health behaviors.
The third barrier to change health behaviors toward preventing NCDs within indigenous communities in Bangladesh is insignificant advocacy for health intervention programs. Whilst health messages can be conveyed through an array of channels, including traditional mass media, and social media, ${ }^{25,52}$ traditional mass media (e.g., television/radio, newspapers) has the potential to spread behavior changing messages and/or health messages quicker and farther than other communication approaches. ${ }^{45}$ Mass media, predominantly radio and television, have swayed individuals' attitude, and behaviors concerning reproductive health through diverse educational programmes. ${ }^{53}$ Research indicated that exposure to mass media was more relevant than socio -economic factors among Mru indigenous women while using $\mathrm{MHCS}^{26}$ Evidence also suggested upholding comprehensive outreach programs with health education to motivate Mru girls to avail $\mathrm{MHCS}^{26}$ Nevertheless, the benefits of assimilating mass media with comprehensive outreach programs to prevent NCDs are hardly realized within the indigenous communities in Bangladesh.

\section{Effective strategies to prevent NCDs}

The health conditions and outcomes of indigenous people in Bangladesh are embedded within their explicit socioeconomic and cultural settings, where they have been raised in. ${ }^{38}$ Adopting some effective strategies, Bangladesh can change health behaviors within indigenous communities. Firstly, Bangladesh should use multifaceted mass media to intensify coverage of the health campaigns among indigenous people. Studies show that using numerous media channels escalates the frequency of exposure to campaign messages. ${ }^{31,45,52,54}$ A study on Garo people displayed that they were highly exposed to television messages than radio and newspaper posts, ${ }^{46}$ which shines a light on potential use of mass media in conveying NCD related health messages to indigenous people. Secondly, Bangladesh needs to underpin different types of stereotyping health beliefs prevalent within indigenous communities and to deliver unidentified details about NCDs to the target communities through mass media. Finally, Bangladesh should understand the causal pathways of health literacy and develop risk-reduction strategies for indigenous patients suffering from NCDs. Mass media campaigns can disseminate well defined behavior altering messages to large communities; ${ }^{54}$ nevertheless, the messages of health campaigns can sometimes provide inaccurate information, which might hinder the purpose of producing health campaigns. ${ }^{52}$ Therefore, observing the execution of the mass media campaigns to make sure that the proposal is being monitored and the campaigns have the ability to respond quickly when hitches develop in the arena is crucial in changing health behaviors among indigenous people in Bangladesh.

\section{Conclusion}

NCD prevalence is steadily increasing among indigenous people in Bangladesh. The NCD burden within indigenous communities, however, is unnoticed as a public health issue by the 'development' agencies in Bangladesh. It is not an instance of mere ignorance, rather a delicacy of 
positive attitude toward indigenous people's health. Intertwined within socio-economic delusions and discrepancies, indigenous people miss out on essential health care to prevent NCDs. As the debate on inequalities arises and unjust behaviors continue, we should recall that the existence of inequalities hampers to facilitate healthy lifestyles and to deliver universal health coverage in Bangladesh. In response to the growing encumbrance of NCDs, Bangladesh government and nongovernment institutions can take necessary measures to implement suitable health literacy programs targeting indigenous peoples' health. Multi-stakeholder and intergovernmental mechanisms and mass media campaigns can be effective options, especially in relation to changing health behaviors of indigenous people. Multifaceted mass media can underpin quintessential health beliefs and convey unidentified details about NCDs in underserved areas of Bangladesh, thus facilitating effective translation of evidence into policy. With effective monitoring and evaluation of planned mass media health programs or campaigns, Bangladesh can set an example for other developing countries encountered with similar health challenges within indigenous communities. Lessons learning from the national negotiations, it can be concluded that that spiritual, emotional, and environmental factors should be assimilated into the indigenous health agenda to improve their health in the future.

\section{Competing interest}

The author declares that she has no competing interest.

\section{References}

1. Cesare MD, Khang YH, Asaria P, Blakely T, Cowan MJ, Farzadfar $\mathrm{F}$ et al. Inequalities in noncommunicable diseases and effective responses. Lancet 2013; 381(9866):585-97.

2. Islam SM, Purnat TD, Phuong NT, Mwingira U, Schacht K, Fröschl G. Non-Communicable Diseases (NCDs) in developing countries: a symposium report. Global Health 2014;10(1):81.

3. Mehan MB, Srivastava N, Pandya H. Profile of non-communicable disease risk factors in an industrial setting. J Postgrad Med 2006; 52(3):167.

4. Mohan V, Mathur P, Deepa R, Deepa M, Shukla DK, Menon GR et al. Urban rural differences in prevalence of self-reported diabetes in IndiaThe WHO-ICMR Indian NCD risk factor surveillance. Diabetes Res Clin Pract 2008; 80(1):15968 .

5. Nongkynrih B, Acharya A, Ramakrishnan L, Ritvik L, Krishnan A, Shah B. Profile of biochemical risk factors for noncommunicable diseases in urban, rural and periurban Haryana, India. J A ssoc Physicians India 2008; 56:165-70.

6. $\mathrm{Ng} \mathrm{N}$, Stenlund H, Bonita R, Hakimi M, Wall S, Weinehall L. Preventable risk factors for noncommunicable diseases in rural Indonesia: prevalence study using WHO STEPS approach. Bull World Health Organ 2006; 84: 305-13.

7. Zaman MM, Bhuiyan MR, Karim MN, MoniruzZaman, Rahman MM, Akanda AW et al. Clustering of non-communicable diseases risk factors in Bangladeshi adults: an analysis of STEPS survey 2013. BMC public health 2015; 15(1):659.

8. Hussain A, Rahim MA, Khan AKA, Ali SMK, Vaaler S. Type 2 diabetes in rural and urban population: diverse prevalence and associated risk factors in Bangladesh. Diabet Med 2005; 22: 931-6.

9. Minh HV, Huong DL, Giang KB. Selfreported chronic diseases and associated sociodemographic status and lifestyle risk factors among rural Vietnamese adults. Scand J Public Health 2008; 36:629-34.

10. Burrows NR, Geiss LS, Engelgau MM, Acton KJ. Prevalence of diabetes among Native Americans and Alaska Natives, 19901997: an increasing burden. Diabetes Care 2000;23(12):1786-90.

11. El Mugamer IT, Ali ZA, Hossain MM, Pugh $\mathrm{RN}$. Diabetes, obesity and hypertension in urban and rural people of bedouin origin in the United Arab Emirates. J Trop Med Hyg 1995; 98(6):407-15.

12. World Health Organization. Health of indigenous peoples. http:/www.who.int/ mediacentre/factsheets/fs326/en/ (accessed October 2016).

13. Islam SM, Mainuddin A, Islam MS, Karim MA, Mou SZ, Arefin S et al. Prevalence of risk factors for hypertension: A crosssectional study in an urban area of Bangladesh. Glob Cardiol Sci Pract 2015; 2015(4):43.

14. Biswas T, Islam A, Rawal LB, Islam SM. Increasing prevalence of diabetes in Bangladesh: a scoping review. Public Health 2016; 138:4-11.

15. Islam SM, Rawal LB, Niessen LW. Prevalence of depression and its associated factors in patients with type 2 diabetes: A cross-sectional study in Dhaka, Bangladesh. Asian J Psychiatr 2015 ; 17:36-41.

16. Zaman MM, Yoshiike N, Rouf MA, Syeed $\mathrm{MH}$, Khan MR, Haque $\mathrm{S}$ et al. Cardiovascular risk factors: distribution and prevalence in a rural population of Bangladesh. J Cardiovasc Risk 2001; 8 (2):103-8.

17. Pakistan Medical Research Council. National Health Survey of Pakistan 1990 94. Islamabad, Pakistan: Pakistan Medical Research Council. Network Publication Service, 1998.

18. Fernandes VL, Kottke TE, Nicholas JJ. Tobacco consumption and coronary artery disease. In: Rao GHR, Kakkar VV (Eds). Coronary artery disease in South Asians. New Delhi, India: Jaypee Brothers, 2001.

19. Zaman K, Naser M, Khan MHA, Habib SH. Association of periodontal disease with lifestyle, diabetes mellitus and oral health care 
practices in an indigenous Bangladeshi population. J diabetol 2015;6(1):5.

20. Biswas S, Sujat P, Syeed A, Mahbub MS, Khan MA, Gupta RD et al. Spectrum of Alcoholic Liver Disease in Tribal Alcoholics of Chittagong Hill Tracts of Bangladesh. J Medicine 2011;12 (1):7-11.

21. Das P, Sotomayor G. WHO and the media: a major impediment to global health? Lancet 2014; 383(9935): 2102-04.

22. Baron RC, Melillo S, Rimer BK, Coates RJ, Kerner J, Habarta $\mathrm{N}$ et al. Intervention to increase recommendation and delivery of screening for breast, cervical, and colorectal cancers by Health care providers: A systematic review of provider reminders. Am J Prev Med 2010; 38(1):110-7.

23. Ahmed S, Creanga AA, Gillespie DG, Tsui AO. Economic status, education and empowerment: implications for maternal health service utilization in developing countries. PloS One 2010; 5(6):e 11190.

24. Islam MR, Odland JO. Determinants of antenatal and postnatal care visits among Indigenous people in Bangladesh: a study of the Mru Community. Rural Remote Health 2011;11 (2):1672.

25. Durkin S, Brennan E, Wakefield M. Mass media campaigns to promote smoking cessation among adults: an integrative review. Tob Control 2012; 21(2):127-38.

26. Islam RM. Utilization of maternal health care services among indigenous women in Bangladesh: A study on the Mru tribe. Women Health 2017; 57(1):108-18.

27. Abdullah N. A survey on Socio-demographic and Health status of Tribal community of Bangladesh: Santals. Honours [thesis]. Dhaka: East West University, 2014.

28. Bangladesh Bureau of Statistics. Statistical Pocket Book of Bangladesh, 2000. Dhaka: Government of the People's Republic of Bangladesh, 2000.

29. Basu SK, Jindal A, Kshatriya GK. Genetic and socio-cultural determinants of tribal health: A Primitive Kutia Knodh tribal group of Phulbani district. ICMR Final Report. Orissa: NIHFW, 1990.

30. Stephens C, Nettleton C, Porter J, Willis R, Clark $\mathrm{S}$. Indigenous peoples' health — why are they behind everyone, everywhere? Lancet 2005; 366 (9479):10-3.

31. Abdullah N. A survey on Socio-demographic and Health status of Tribal community of Bangladesh: Santals. Masters [thesis]. Norway: University of Tromsø Norway, 2006. Available from: Munin Open Research Archive.

32. Lee SY, Arozullah AM, Cho YI. Health literacy, social support, and health: a research agenda. Soc Sci Med 2004; 58(7):1309-21.
33. Sayeed MA, Banu A, Haq JA, Khanam PA, Mahtab H, Khan AKA. Prevalence of hypertension in Bangladesh: effect of socioeconomic risk factor on difference between rural and urban community. Bangladesh Med Res Counc Bull 2002;28(1):7-18.

34. Islam MR, Islam MA, Banowary B. Determinants of exposure to mass media family planning messages among indigenous people in Bangladesh: A study on the Garo. J Biosoc Sci 2009; 41(2):221-9.

35. Sayeed MA, Khanam PA, Hussain MT, Rhaman MM, Sayeed S, Begum T et al. Diabetes and Hypertension in a Santhal Tribe in Bangladesh: A Population Based Study. Int J Diabetes Mellit 2014; 4(2):133 -140

36. Subramanian SV, Smith GD, Subramanyam M. Indigenous health and socioeconomic status in India. PLoS Med 2006; 3(10): e 421.

37. Williams DR, Neighbors HW, Jackson JS. Racial/ethnic discrimination and health: Findings from community studies. Am J Public Health 2003; 93(2):200-8.

38. Islam MR, Sheikh MA. Cultural and socioeconomic factors in health, health services and prevention for indigenous people. Antrocom Online J Anthropol 2010; 6(2):263-73.

39. Sayeed MA, Mahtab H, Khanam PA, Ahsan KA, Banu A, Rashid AB et al. Diabetes and impaired fasting glycemia in the tribes of Khagrachari hill tracts of Bangladesh. Diabetes Care 2004;27 (5):1054-9.

40. Fatema K, Islam N, Ali L. Cardiovascular risk factors among Santal population in Bangladesh. $J$ Epidemiol Community Health 2011;65 (Suppl 1):A453.

41. Uddin MJ, Alam N, Sarma H, Chowdhury MA, Alam DS, Niessen L. Consequences of hypertension and chronic obstructive pulmonary disease, healthcare-seeking behaviors of patients, and responses of the health system: a populationbased cross-sectional study in Bangladesh. $B M C$ public health 2014;14(1):547.

42. Parr JD, Lindeboom W, Khanam MA, Koehlmoos TL. Diagnosis of chronic conditions with modifiable lifestyle risk factors in selected urban and rural areas of Bangladesh and sociodemographic variability therein. BMC Health Serv Res 2011;11(1):309.

43. Lorenc T, Petticrew M, Welch V, Tugwell P. What types of interventions generate inequalities? Evidence from systematic reviews. $J$ Epidemiol Community Health 2013; 67(2):190 -3 .

44. Rahman SA, Kielmann T, McPake B, Normand C. Healthcare-seeking behaviour among the tribal people of Bangladesh: can the current health system really meet their needs? $J$ Health Popul Nutr 2012; 30(3) :353-65.

45. Randolph W, Viswanath K. Lessons learned from public health mass media campaigns: 
marketing health in a crowded media world. $A n-$ nu Rev Public Health 2004; 25:419-37.

46. Kabir M, Islam MA. The impact of mass media family planning programmes on current use of contraception in urban Bangladesh. J Biosoc Sci 2000; 32(3):411-9.

47. Barker DJ. The developmental origins of chronic adult disease. Acta Paediatr Suppl 2004; 93 (446):26-33.

48. Harding JE. The nutritional basis of the fetal origins of adult disease. Int J Epidemiol 2001;30 (1):15-23.

49. Islam MA, Islam MR, Banowary B. Sex preference as a determinant of contraceptive use in matrilineal societies: A study on the Garo of Bangladesh. Eur J Contracept Reprod Health Care 2009;14(4):301-6.
50. Birmeta K, Dibaba Y, Woldeyohannes D. Determinants of maternal health care utilization in Holeta town, central Ethiopia. BMC Health Serv Res 2013 ;13(1):256.

51. Ahmed S, Creanga AA, Gillespie DG, Tsui AO. Economic status, education and empowerment: implications for maternal health service utilization in developing countries. PLoS One $2010 ; 5(6): \mathrm{e} 11190$.

52. Weinreich NK. Hands-on social marketing: a step-by-step guide to designing change for good. London: Sage Publications, 2011.

53. Noar SM. A 10-year retrospective of research in health mass media campaigns: Where do we go from here? J Health Commun 2006;11(1):21-42.

54. Wakefield MA, Loken B, Hornik RC. Use of mass media campaigns to change health behaviour. Lancet 2010; 376(9748):1261-71. 